\title{
Advances in Cervical Screening Technology
}

\author{
Mark H. Stoler, M.D.
}

Department of Pathology, University of Virginia Health System, Charlottesville, Virginia

\begin{abstract}
The Pap smear unquestionably is a successful screening test for cervical cancer. However, recent advances in technology have raised questions regarding whether the conventional Pap smear is still the standard of care. This article relates issues of screening and cost-effectiveness to the state of the art in thin layer preparations, cytology automation, human papillomavirus screening, human papillomavirus vaccines, and other cervical screening adjuncts. Perhaps nowhere in medicine is clinical decision making being more strongly influenced by market and other external forces than in cervical cytopathology.
\end{abstract}

KEY WORDS: Advances, Cancer, Cervix, Human papillomavirus, Neoplasia.

Mod Pathol 2000;13(3):275-284

\section{SCREENING CONCEPTS AND PERSPECTIVES}

The Pap smear is the best example of a successful cancer screening $(1,2)$. Since the late 1940 s, the coincidence of evolving technology, an accessible target organ, and a relatively long preinvasive development time for this disease with a historically bad outcome provided the impetus for cytologic screening. As is often noted, the Pap smear has never been subjected to a formal clinical trial to determine its efficacy. Rather, early anecdotal positive experience, combined with pressing clinical need, leads to its widespread implementation (3-5).

Approximately 500,000 cases of cervical cancer occur each year. In contrast to the situation in the screened populations, cervical cancer still ranks as the first or second most frequent carcinoma in women (fighting for number 1 with breast cancer) worldwide. In addition to these features, the effectiveness of treatment of the preinvasive form of cervical cancer combined with the low morbidity of treatment facilitated the decrease in cancer in screened populations. The widely quoted $20 \%$ false-negative grade for a single Pap test does not

Copyright $($ C 2000 by The United States and Canadian Academy of Pathology, Inc.

VOL. 13, NO. 3, P. 275, 2000 Printed in the U.S.A.

Date of acceptance: November 8, 1999. take into account that each annual test is an independent event. Consequently, in an appropriate target population, the risk for missing serious disease with three annual consecutive screenings is approximately $1 \%$. At least half of false-negative Pap smears are due to inadequate sampling. Either the cells are not collected or they are not present on the slide. One third to one half are due to errors in the screening process involving locator or interpreter error. Much of the discussion on available new technology that follows is focused on lowering the false-negative rate, addressing issues of sampling, sample preparation, or screening/quality control.

The following background data are derived from several sources, primarily the U.S. Census Bureau, the American Cancer Society (ACS), the College of American Pathologists (CAP), and several online cancer databases (6). They are included to provide some perspective on the advances to be discussed. Of the approximately 272 million people in the United States, 139 million are female. If we assume that the major target population for cervical cancer screening includes only women between the ages of 15 and 70, then the target population size is reduced to approximately 95 million. A common estimate of the volume of Pap smears performed annually is approximately 50 million. Therefore, only approximately half of the population is getting annual screening. Of course, this estimate does not reflect issues of maldistribution whereby a population subset is highly screened with multiple repeat examinations versus a fairly large subset of poor, uninsured, or ethnic minorities who have never been screened or are screened inadequately. An estimate of the distribution of cytologic diagnoses extrapolated to the U.S. population, taking into account reasonable estimates of the Pap smear falsenegative fraction per diagnostic category, is presented in Table 1.

The American Cancer Society estimates that there will be 12,800 cases of cervical carcinoma in the United States with approximately 4,600 deaths. In unscreened populations, cervical cancer incidence ranges from 30 to 40 in 100,000 to as high as 1 in 1,000, compared with the current U.S. rate of approximately 5 in 100,000. Hence, screening has 


\begin{tabular}{|c|c|c|c|c|c|}
\hline & \% Frequency & $\begin{array}{l}\text { Estimated } \\
\% \mathrm{FNF}\end{array}$ & $\begin{array}{l}\text { Corrected for } \\
\text { FNF Frequency }\end{array}$ & $\begin{array}{l}\text { Multiplied by } \\
50 \text { Million } \\
\text { Pap Smears }\end{array}$ & $\begin{array}{c}\text { Divided by } \\
0.52 \text { (Females) }\end{array}$ \\
\hline ASCUS & 2.8 & 20 & 3.36 & $1.68 \mathrm{E}+06$ & $3.23 \mathrm{E}+06$ \\
\hline LSIL & 1.97 & 10 & 2.17 & $1.09 \mathrm{E}+06$ & $2.10 \mathrm{E}+06$ \\
\hline HSIL & 0.51 & 10 & 0.55 & $2.75 \mathrm{E}+05$ & $5.29 \mathrm{E}+05$ \\
\hline SCC & 0.026 & 5 & 0.027 & $1.35 E+04$ & $2.60 \mathrm{E}+04$ \\
\hline AdCa & 0.0046 & 10 & 0.005 & $2.50 \mathrm{E}+03$ & $4.81 \mathrm{E}+03$ \\
\hline ASCUS:LSIL & NA & NA & NA & 1.54 & NA \\
\hline ASCUS:SIL & NA & NA & NA & 1.23 & NA \\
\hline LSIL:HSIL & NA & NA & NA & 3.96 & NA \\
\hline
\end{tabular}

Data based in part on a CAP study of 1,741,515 smears from 338 laboratories and extrapolated to U.S. population. (Cancer data corrected for American Cancer Society numbers.)

FNF, false negative fraction; ASCUS, atypical squamous cells of undetermined significance; L/HSIL, low-/high-grade squamous intraepithelial lesion; SCC, squamous cell carcinoma; AdCa, adenocarcinoma.

effected up to a $90 \%$ reduction in the incidence of cervical cancer. Likewise, Gustafsson et al. $(7,8)$ performed a careful study of worldwide databases to get an estimate of the incidence rate of cervical cancer in various populations before the effects of screening. They analyzed more than 83,000 cases, and their studies provide a good statistical profile of cervical cancer worldwide. The mean age at peak incidence of diagnosis is $54 \pm 8$ years, and the mean range from the earliest onset of cervical cancer $(26 \pm 3)$ to peak is $28 \pm 7$ years. The shape of the curve of cancer incidence is interesting and suggests that either exposure to the cancer-causing agents decreases with age or target cells are less susceptible to malignant transformation with age. Compared with the worldwide data, the U.S. and other screened populations have approximately a decade earlier mean as well as a questionable rising incidence, speculated to be due to the effect of sexual behavior on maturing cohorts.

From Table 1, the pool of all cytologic abnormalities (atypical squamous cells of undetermined significance [ASCUS] and above) is only $5.9 \%$ of the population. The corresponding number for lowgrade squamous intraepithelial lesions (LSIL) $+=$ $2.7 \%$ and for high-grade squamous intraepithelial lesions (HSIL) $+=0.56 \%$. Thus, despite widespread "negative" publicity, the Pap smear has done a remarkable job of finding the "needles in the haystack." This success is despite that the test is still performed very much as originally invented. Indeed, simple but major early advances included the conversion from a vaginal pool specimen to direct cervical sampling, an improved differential staining technique, and the training of a highly skilled workforce of dedicated cytotechnologists, which have combined to bring about the current situation-a Pap test so good that the general population expects it to be perfect.

No test is perfect, including the Pap smear. In the past decade, significant technical advances have presaged the possibility of improving what is already a very good test. These advances have ad- dressed problems of improving sample collection, specimen preparation, screening locator errors, fatigue, and so forth to drive down the false-negative fraction while increasing the sensitivity and specificity of this screening test. Some newer technologies attempt to "threaten" the primacy of the Pap smear for cervical cancer screening. In the future, given the advances in our understanding of cervical cancer pathogenesis, widespread human papillomavirus (HPV) vaccination may make cervical cancer screening a thing of the past for our children or grandchildren. What follows addresses the currently available technologies and the questions of whether these technologies help us do better in cervical cancer screening while trying to balance this against a perspective of "if we can do better, is it worth the cost?"

Recently, Melamed et al. (9) attempted to evaluate issues of cost in cervical screening technology. They stated that any cost-effectiveness analysis should take a societal as well as a medical perspective. Assessing the marginal impact of any new technological advance should be the primary goal of such analyses. Certainly, the goal of any new technology should be to improve the health of the population to which the technology is applied while hopefully reducing costs. In reality, there are very few examples of recently introduced new technology in which these goals have been achieved. A stringent requirement to reduce cost can have a markedly adverse effect on the introduction of any new technology. If price is the only determinant of technological implementation, such a strict requirement may freeze current technology in place. Price plus value, emphasizing the long term, is a much harder but realistically needed perspective. A full analysis of cost-effectiveness is beyond the scope of this article $(10,11)$. However, in a screened population such as in the United States, at least $50 \%$ of the cancers occur in patients who have never had a single screening examination. Another 25 to $33 \%$ occurs in people who are inadequately screened. It should be obvious then, that any im- 
provement in screening technology will not significantly affect the cervical cancer rate because fewer than 10 to $15 \%$ of the cancers occur in patients who are being adequately screened even with our current "primitive" technology. In addition, the current U.S. screening effort combined with the cost of therapy costs approximately $\$ 3$ to 5 billion a year. A $\$ 10$ "improvement" equals $\$ 1$ billion of additional health care cost when applied to the entire population at risk. Without effectively bringing more patients into the screening pool, a perfect improvement could be expected to save at most 500 to 1,000 lives at a cost of $\$ 1$ million or more per case. Is society willing to pay this price? Are there ways of improving the distribution of the health care dollar such that new technology may be implemented within the current multibillion-dollar framework? I do not have answers to these questions, but the following observations conclude my remarks on screening. Contrast the Pap smear with another common screening test, serum prostate specific antigen (PSA) analyses.

Costs for a PSA range between $\$ 10$ and $\$ 15$, depending on whether indirect costs are included in the analysis. The current charge at many institutions is approximately $\$ 60$, although actual reimbursement is again variable depending on the payer. Even at $50 \%$ reimbursement (typical of Medicare), this test is reimbursed at up to five times the rate of a screening Pap smear: This for a test that is nearly completely automated and requires only a blood draw. The benefits of widespread PSA screening are at best controversial, and the target population is much more highly selected.

In contrast, the current cost for a conventional Pap smear is approximately $\$ 10$ per test, and the charge for all but the abnormal cases, in which a pathologist is involved, is approximately twice that at $\$ 20$ per test. These costs and charges do not reflect that Pap smears continue to be used as a "loss leader" in many institutions. In addition, many Pap smears are not billed separately as a clinical laboratory test. It is difficult to get exact numbers, because this is one of the deeply buried secrets in the interaction between pathology laboratories and clinicians. For many patients, the Pap smear is paid for directly by the clinician, usually at a minimal rate. The clinician then charges the patient the usual "exam + Pap smear" collection/ interpretation fee and pockets the difference. Thus, there is a strong negative incentive to reimburse Pap smears at what even Medicare thinks is a reasonable technical charge, because every cent spent on increased Pap reimbursement is money taken directly from the clinician's pocket. In my opinion, a significant fraction of the dollars needed to implement new technology is tied up in this quagmire, and such a system calls into question pronounce- ments from some clinical professional organizations that state that new technologies are unproved or not cost-effective and therefore should not be implemented. Clearly, the Pap smear is an undervalued test!

If money cannot be shifted from one available pot to the another, then what alternatives exist for freeing dollars to implement new technologies or to reach effectively more of the population? The only obvious answers include screening less frequently and screening a different proportion of the population based on some preselection criteria. Regarding the former, Frame and Frame (12) stated that the only significant factors that should determine the frequency of screening are the "window" of opportunity reflecting the length of time necessary to develop the target disease and the sensitivity of the test. It is surprising that the incidence of the disease in a population does not affect the efficacy of screening. Frame estimated, based on a review of the literature, that the overall sensitivity of a single Pap examination is $80 \%$. The window from acquisition of mild cervical dysplasia to the development of carcinoma in situ and/or invasive cancer is at least 6 to 10, if not 20, years. Given that model, screening every 3 years detects $96 \%$ of patients who are at risk. This model compares well with the international data used in his study as a comparison group. The analyses clearly show that there is little to be gained by screening more frequently than every 3 years. Even recent estimates of only 50\% Pap smear sensitivity may not justify annual screening (13). Counterintuitively, more frequent screening may ultimately decrease the sensitivity of the given test. This is because frequent screening filters out the "easy" cases and leaves cases that are harder to identify and diagnose in the residual population. An examination of their formula and assumptions clearly shows that "an ounce of prevention is better than a pound of cure, but 2 ounces is not better than 1." Although such an analysis clearly points to a potential source of funds for technological innovation, changing the behavior patterns of populations seems to be a daunting task.

Given the above issues, what "advances" are currently available or on the horizon to address the problems with Pap smears? The problems, for the most part, are centered on decreasing the falsenegative fraction, thereby increasing sensitivity while hopefully not compromising specificity. Many of the current device-based advances center on addressing two issues: optimization of the cellular sample and improvement in screening the cellular sample for abnormality. Most consumers do not appreciate the complexity of the Pap smear screening process. Simple things that can be done to improve the quality of the cellular sample, including appropriate patient preparation (e.g., trying 
to avoid sampling at menses), can greatly improve the signal-to-noise ratio in the average Pap test. This article does not analyze the pros and cons of different sampling devices. Suffice it to say that the amount of material does vary widely with sampling device and that sampling devices that adequately collect material across the squamocolumnar junction (transformation zone) improve accuracy.

\section{THIN LAYER TECHNOLOGIES}

The attractions of thin layer technologies include improvements in sampling, fixation, staining, and background. In essence, most of the variables in slide quality are removed from the realm of the sample collector and placed under more stringent control within the laboratory.

The average Pap smear slide contains between 50,000 and 300,000 cells. Depending on the patient, a significant proportion of these cells may be inflammatory cells and/or red cells. In contrast, DNA analysis of the average Pap collection demonstrates that more than 1 million cells are routinely collected in the total sample. Thus, as little as $5 \%$ of the sample may actually make it onto the slide; with the traditional Pap sampling method, this is not a random subset of the total sample collected. The advantages of thin layer technologies address all of the problems in the preanalytic stage of the Pap smear. The entire sample is placed directly into a vial of liquid fixative, optimizing fixation. Randomization of the sample ensures a more representative sampling on the slide submitted for screening. Optimization of fixation and staining addresses the significant fraction of ASCUS diagnoses related to obscuring factors or poor fixation. In May 1996, Cytyc Corporation received Food and Drug Administration (FDA) approval for the ThinPrep 2000 System. As of this writing, ThinPrep is the only monolayer system approved for use in gynecologic cytology. A competing technology, AutoCyte Prep (AutoCyte, Inc.) is in the final stages of premarket approval from the FDA and most likely will be available by the time this is published.

A review of the available literature for the ThinPrep 2000 System and its predecessor, ThinPrep Beta, in trials that assessed more than 80,000 samples reveals that the ThinPrep technology produces slides that are superior to a conventional Pap smear's in finding cases of abnormality (14-28). Improvements in sensitivity are noted primarily for cases of ASCUS and LSIL. However, some studies have demonstrated improvements in finding cases of high-grade abnormality as well. No study demonstrated inferiority for the monolayer technology. All studies demonstrated at least equivalence, and most demonstrated improvement. Furthermore, virtually all of the studies are biased against the new technique in that they are so-called split-sample studies in which the conventional Pap smear is prepared from the cytologic sample first and the remainder is suspended in the liquid buffer system. More dramatic improvements in sensitivity, particularly for high-grade lesions, as well as specimen adequacy, have been demonstrated with recent direct-to-vial studies. Some similar preliminary data are available for the AutoCyte Prep. Concerns have been raised about the adequacy of the ThinPrep for the detection of glandular lesions; the original FDA trial showed a decrease in specimen adequacy for the presence of an adequate endocervical component. More recent data suggest that these concerns are an artifact of two processes. Some of the softer cervical "broom" devices may not adequately sample the transformation zone, particularly if inappropriately used. Such devices may also be inappropriate for certain patients, depending on their cervical anatomy. Furthermore, the more recent direct-to-vial studies demonstrate significant improvements in the number of specimens judged to be adequate for an endocervical component.

The obvious disadvantages of thin layer technologies are the trade-off in sample preparation time and cost in the laboratory. These negatives may be compensated by an improved screening environment with clear cellular visualization, less fatigue, and perhaps decreased screening time as a result of the smaller number of cells and smaller cell visualization area on the slide. However, the significance of even a single abnormal cell in these relatively decreased cellularity preparations is increased. Thus, marked decreases in screening time may not be possible as technologists may spend more time looking at fewer cells to find the small population of abnormal cells present on the slide. The other obvious problem is the markedly increased cost associated with these preparations. Cost-benefit analyses notwithstanding, the FDA has granted Cytyc claims that allow the ThinPrep to be a replacement for the conventional Pap smear and cite that it is significantly more effective than the conventional Pap smear. Currently, the ThinPrep method seems to have penetrated approximately 10 to $15 \%$ of the Pap smear market.

\section{SCREENING AUTOMATION}

For the past 3 years, two devices, Neopath's AutoPap 300 QC and Neuromedical Systems' PapNet, have been available for the quality control rescreening of negative Pap smears. For the past year, the AutoPap System has been the only device approved for primary screening. The PapNet System was undergoing clinical trials as a primary screener (see 
below). AutoCyte has a screener that is tightly linked to the AutoCyte Prep method. There are a few other companies that are still earlier in the development process $(16,21,29)$.

The AutoPap System allows up to $25 \%$ of the most normal slides that are scanned into the system to be sorted out for no further human review. The concept that a machine, without human input, can review a cytopathology specimen is potentially a major advance in anatomic pathology practice (3033). As automated blood smear analyzers had tremendous impact on the hematology laboratory, so, too, could automation have a tremendous impact on the conventional practice of cytopathology. In the FDA clinical trial supporting the use of the AutoPap, Wilbur et al. (33) conducted a two-armed prospective study involving 25,000 conventional Pap smears. This study compared AutoPap-assisted practice at a $25 \%$ sort rate combined with a $15 \%$ AutoPap-directed quality control rescreen to conventional practice including the Clinical Laboratories Improvement Act-mandated $10 \%$ random rescreening. The ranking scores generated by the AutoPap for the human reviewed fraction were provided to the cytotechnologist. This critical part of the protocol seems to have modified technologists' behavior/vigilance for the better. The results of this study demonstrate statistically significant improvements in the detection of abnormal slides at the levels of ASCUS+, LSIL, and LSIL+, as well as statistical equivalence for HSIL+. In addition, there was an average of $16 \%$ improvement in the falsepositive rate. Thus, AutoPap-assisted practice not only improved sensitivity but also simultaneously improved specificity. Neopath's achievement of breaking through the automation barrier with a primary screening instrument in cytopathology is highly significant. The potential for maintaining or increasing capacity in cytopathology laboratories at a time when skilled cytotechnologists are in diminishing supply yet the government is focusing efforts to increase the number of people availing themselves of the Pap smear screening system should support its potential use. Of course, new technology does not come without some increase in cost. However, Neopath based the claims granted by the FDA for the use of the AutoPap System as a primary screener on a very conservative presentation. The data contained in the primary screening trial may actually support statistical superiority or equivalence at higher sort rates. Overseas implementations of the AutoPap technology, particularly in areas where cytotechnology services are more poorly developed, demonstrate the ability of the system to improve markedly the quality of cytopathology services while simultaneously decreasing workload.

The PapNet System that was undergoing clinical trials both in Europe and in the United States for use in primary screening of Pap smears is somewhat different from the system that received approval for quality control rescreening (34-39). Like the AutoPap, the new PapNet system places the screening/scanning instrument in the laboratory. This solves a major problem with the previous system, which required users to ship their slides, often at great distance and expense, to a remote scanning laboratory. The new scanner and software presents on a computerized review station 128 images for each slide that demonstrate areas with the highest likelihood of abnormality. Triage of slides into "no review" and "review" is determined by the cytotechnologist's impression on the workstation. It is important to note that in these trials, thin layer preparations, as well as conventional Pap smears, were also being tested. Likewise, Neopath is conducting clinical trials to remove a major impediment to further implementation of the AutoPap technology, because thin layer preparations and AutoPap are currently mutually exclusive technologies. However, it should be obvious that the two technologies greatly complement each other. The superior cytologic preservation and decrease in overlapping cell presentations of thin layer techniques can only make the job of these very sophisticated imaging computers much easier.

The state of screening automation is first generation. Besides the obvious improvements in sort rates that can potentially be brought about by the use of combined thin layer and automation technology, other potential improvements are envisioned for the near future. These include sitedirected screening, whereby the "alarms" by which these automated systems rank and/or triage slides are communicated to the cytotechnologist in a manner that directs him or her to the areas of the slide with the highest likelihood of abnormality. Such an AutoPap-based system that generates a "PAPMAP" has already been implemented in Taiwan with impressive results. Interfacing such a system with a computer-controlled stage such as Pathfinder (Neopath) could even further improve efficiency in the screening process.

Of course, all of this technology is contingent on the survival of these companies. As in many new technology arenas, the cytopathology automation field is rapidly evolving. In the 3 months since the presentation at the USCAP meeting, Neuromedical Systems, Inc., has declared bankruptcy. Its intellectual property has been sold to Autocyte, Inc. The field has further consolidated with the announced merger of Autocyte, Inc., and Neopath, Inc. Thus, from four competitors, the marketplace is reduced to just two. It would be a shame if the decades of work that have now culminated in actual working cytopathology automation processes were ended prematurely or terminated inappropriately because 
of the severe problems induced by continued underreimbursement for Pap smear services.

\section{HPV SCREENING}

The estimated overall HPV prevalence in the U.S. target population is approximately $20 \%$. The prevalence varies greatly with age (Table 2). These data have implications for a discussion about the utility of HPV testing as a screening procedure.

It is clear that virtually all lesions encompassed by the term "cervical neoplasia" are HPV associated. The epidemiologic and molecular evidence supporting this is convincing $(40,41)$. Epidemiologic studies demonstrate that a positive HPV test is the most powerful independent risk factor for the development of both cervical dysplasia and invasive cancer. Once HPV status is accounted for, the relative risk associated with traditional factors, such as sexual behavior, becomes insignificant. In limited studies, HPV infection precedes and predicts for the development of cervical precancer as well as invasive cancer. Furthermore, virtually $100 \%$ of invasive carcinomas from around the world have been shown to be associated with a limited spectrum of HPV types (42).

Given the strength of these associations, an obvious question is whether screening for HPV using some sort of molecular diagnostic test would be superior for selecting the population at risk for cancer development (43-46). The answer to this apparently simple question is, unfortunately, complex. Part of the problem is technical. Which HPV test should be used? HPV testing, as all molecular diagnostics, is continually evolving. Until recently, there has been only one commercially available FDAapproved test for HPV, the Hybrid Capture tube test (HCT) marketed by Digene Diagnostics. The sensitivity, specificity, and predictive values of the "tube" test with a $10 \mathrm{pg} / \mathrm{ml}$ cutoff value for a group

TABLE 2. Estimates of Numbers of HPV-Infected Females Based on U.S. Census Data Projections for July 1999 and National Cancer Institute Estimates of HPV Positivity by Age

\begin{tabular}{rcccc}
\hline Age & $\begin{array}{c}\text { \# of } \\
\text { Females } \\
\text { Divided by } \\
1000\end{array}$ & $\begin{array}{c}\text { \% of Total } \\
\text { Females }\end{array}$ & $\begin{array}{c}\text { Estimated } \\
\text { HPV } \\
\text { Prevalence }\end{array}$ & $\begin{array}{c}\text { Total } \\
\text { HPV/1000 }\end{array}$ \\
\hline $0-10$ & 19,091 & 13.71 & $1.00 \%$ & 190.91 \\
$11-19$ & 19,195 & 13.78 & $20.00 \%$ & 3839 \\
$20-29$ & 17,864 & 12.82 & $40.00 \%$ & 7145.6 \\
$30-39$ & 21,204 & 15.22 & $20.00 \%$ & 4240.8 \\
$40-49$ & 21,020 & 15.1 & $10.00 \%$ & 2102 \\
$50-59$ & 15,126 & 10.9 & $5.00 \%$ & 756.3 \\
$60-69$ & 10,647 & 7.65 & $5.00 \%$ & 532.35 \\
$70-79$ & 9,188 & 6.6 & $5.00 \%$ & 459.4 \\
$80-89$ & 4,796 & 3.4 & $5.00 \%$ & 239.8 \\
$90-99$ & 1,105 & 0.8 & $5.00 \%$ & 55.25 \\
$100+$ & 56 & 0.04 & $5.00 \%$ & 2.8 \\
\hline
\end{tabular}

HPV, human papillomavirus. of 11 to 13 high-risk viruses have been fairly well characterized (47-49). Compared with polymerase chain reaction (PCR) analysis using Ll consensus primers, the HCT has a lower sensitivity. However, the HCT is more specific for the presence of clinically detectable cervical abnormalities compared with PCR, which, because of its higher sensitivity, picks up a significantly higher proportion of patients without clinically detectable disease.

As noted previously, molecular technologies continue to evolve rapidly. The newest iteration of the HCT (HC II, approved in March 1999) is relatively semiautomated, uses a microtitre format, and has up to 50 times the analytic sensitivity of the current test. Whether the improved sensitivity is of clinical benefit greatly depends on whether one is using the test for screening or diagnosis/triage and on the population characteristics. The interplay among sensitivity, specificity, and disease prevalence needs to be kept in mind when evaluating the utility of any test. Likewise, PCR/amplification technologies are rapidly evolving. In addition, the expanding sequence database of all relevant HPVs makes it likely that the new powerful "DNA-chip" technologies may replace or augment current HPV testing methods.

Might HPV testing be a better screening method? This question has been most thoroughly examined by workers in the Netherlands, who have proposed using an extremely sensitive PCR-based method as the first step in a cervical cancer screening program (50-52). If one were designing a cervical cancer screening program from scratch, this approach makes a tremendous amount of sense. Nearly $100 \%$ of the pathology of interest is HPV positive. Conversely, if a sufficiently sensitive screening test showed that an individual was not HPV positive, then the incidence of disease would be so low as to make screening nearly worthless. Considering the high prevalence of HPVs in the pathology of interest and the relatively long time frame from acquisition of infection until the development of cervical cancer, the relative value of initial triage based on HPV status is obvious. The lower the prevalence of HPV in the population to be screened, the better the performance profile of an extremely sensitive HPV screening test. For instance, the incidence of cervical cancer in women who are younger than 25 to 30 years is extremely low, and the prevalence of HPV in the United States drops from approximately $40 \%$ at age 20 to 10 to $20 \%$ at age 30 to 40 (or as low as 4 or $5 \%$ at age 30 in the Netherlands). Under these conditions, it may not make sense to spend resources on screening young women, most of whom develop only transient low-grade lesions. The Dutch proposal seeks to screen the entire population at age 30 with the most sensitive HPV test available combined with a single cytologic screen- 
ing. Patients whose results are positive on either test would be entered into a program of more intense routine screening, whereas the "double negative" patients would be returned to the general population pool that would then be screened on a long-interval basis of 5 to 10 years. Again, if the prevalence of detectable virus is low and the disease prevalence is also low, such a system makes for extremely rational triage and resource utilization. The arguments become even stronger if the cost and reliability of the HPV test become comparable to cytologic methods. Indeed, in some recent studies, HPV testing seemed more reliable than the Pap smear because of superior sensitivity in identifying patients with cervical abnormalities. For instance, a large recently published triage study of ASCUS patients evaluated HC II testing for "oncogenic" HPVs versus repeat smear as an index for colposcopic referral (53). The sensitivity for HSIL or greater in the HPV testing arm was $89.2 \%$ with a specificity of $64.1 \%$. In contrast, the sensitivity for repeat Pap smear was $76.2 \%$. This difference approached statistical significance. This and other studies strongly suggest that HPV testing will evolve into routine clinical practice. Furthermore, prospective studies that address a rational basis for HPV primary screening are needed and planned in the Netherlands and at other sites. Whether such a program could be tested in the United States is questionable because of the relative mobility of the U.S. population and the strongly ingrained emphasis on annual Pap smear screening.

\section{HPV VACCINES}

The recognition that HPVs are the primary cause of cervical cancer strongly raises the possibility of the use of HPV vaccines for both treatment and prophylaxis of cervical cancer (54-62). A successful prophylactic HPV vaccine could virtually eliminate the need for cervical cancer screening programs. This admirable long-term goal is just possibly coming into reach.

There are more than 100 types of HPVs, more than 30 of which are prevalent in the cervix. It is unclear whether immunity to any specific type provides cross-reactive immunity to other types. Thus, the ultimate vaccine likely may be a complex polyvalent mixture. Until recently, the lack of an abundant source of HPV antigens markedly impeded vaccine development. However, recombinant methods that are capable of generating viruslike particles that contain the HPV L1 and L2 capsid proteins have been the major technical advance promoting HPV vaccine development. Studies performed in animals reveal consistent and promising findings for the development of a prophylactic HPV vaccine. Vaccines developed in rabbits, cows, and dogs all show great promise. Canine oral papillomaviruses (COPVs) are effectively prevented by intradermal injection in the footpad of either a formalin inactivated COPV wart extract or COPV L1 viruslike particles. Immunization of approximately 60,000 beagles during a 3-year period resulted in complete protection against naturally acquired COPVinduced warts.

Approximately $80 \%$ of HPV cancers are associated with a limited type spectrum of HPV 16, 18, 31, and 45 . Several vaccine trials, most initially targeting HPV 16, are undergoing Phase I and Phase II testing. Obviously, the long natural history of both HPV infection and cervical cancer, together with the fact that the optimal target population involves young persons before the onset of sexual activity, complicates the development of such vaccines. However, the potential success of an HPV vaccine program could produce the first example of true cancer prophylaxis and ultimately lead to the elimination of the entire cervical cytology screening system.

\section{PAP SMEAR REPLACEMENTS}

A growing literature sights the shortcomings of the Pap smear, focusing on the causes of falsenegative smears and the problem of cervical cancer in the 25 to $33 \%$ of individuals who have been screened. Much of the previous discussion has been directed at technologies that try to rectify that situation. There are still other approaches $(63,64)$ : those that improve direct visualization of the cervix, many in a manner similar to colposcopy, and those that rely on nonvisual or biophysical analyses that seek to distinguish and even grade the normal/ reactive versus the neoplastic cervix.

Among the visualization methods short of fullblown colposcopy, the one most widely known is cervicography $(65,66)$. This patented technique, available exclusively through National Testing Laboratories (Fenton, MO), is a standardized photograph of the cervix under acetic acid-enhanced visualization, which yields two images that are interpreted centrally by licensed colposcopy experts. The grading system used has undergone evolution mainly to improve specificity. Cervicography has been repeatedly reported to be more sensitive and less specific than cytology. Note that in my opinion, there is a bias in much of this literature in that the Pap smear for comparison is taken at the same time as the cervicogram. A vigorously collected smear could affect the quality of the subsequent image. Cervicography seems to work best as a Pap smear complement, as the two together have a better sensitivity/specificity profile than either alone. How- 
ever, few data compare the utility of this technique with an enhanced Pap smear using automation and/or thin layer methods. The same can be said for all of the other methods mentioned next.

Speculoscopy is a variation of colposcopy that uses blue-white chemiluminescent light along with acetic acid and magnification to examine the cervix. Very limited published data are available on this technique, which relies on established colposcopic skills (67). Prospective trials on screening populations with appropriate controls have yet to be performed.

Polarprobe is another adjunctive or potential screening technique. The Polarprobe is a portable optoelectronic device that differentiates tissue types on the basis of voltage decay and multiwavelength light scatter. Readings are taken by applying the probe directly to the surface of the cervix, and the signals are interpreted immediately by a notebook computer that relates the patterns to algorithms for six tissue types. Limited studies have shown reasonable concordance with colpohistology. This device is undergoing trial for FDA approval as a screening adjunct. The attraction is the potential for immediate diagnosis, which could have significant utility in areas in which cytology services are lacking.

Several other devices are undergoing development and testing on the basis that, similar to Polarprobe, biophysical properties can be measured in vivo/in situ and can discriminate the healthy from the pathologic cervix. Infrared spectroscopy, nuclear magnetic resonance spectroscopy, and laser-induced fluorescence all demonstrate some technical basis for clinical trials (68-71).

Obviously, all of these approaches still require the patient to have a cervical examination. Clearly, patients who are willing to submit themselves to cervical screening are not the problem. In underdeveloped areas, even simple visual inspection or enhanced inspection with a flashlight after the application of vinegar can be used to downstage cervical cancer and improve outcome. The dilemma in ultimately using any or all of the new technologies is tied to cost-effectiveness analyses and the strength of medical arguments for versus the reluctance of payors to support implementation.

\section{REFERENCES}

1. National Institutes of Health Consensus Development Conference statement on cervical cancer, April 1-3, 1996. Gynecol Oncol 1997;66(3):351-61.

2. Recommendations for cervical screening 1997. Members of the Working Party on Cervical Screening. N Z Med J 1998; 111(1062):94-8.

3. Herbert A. Is cervical screening working? A cytopathologist's view from the United Kingdom [see comments]. Hum Pathol 1997;28(2):120-6.
4. Noller KL. In defense of the Pap smear [editorial]. Obstet Gynecol Surv 1998;53(5):261.

5. Patnick J. Has screening for cervical cancer been successful? Br J Obstet Gynaecol 1997;104(8):876-8.

6. Jones BA. Rescreening in gynecologic cytology: Recreening of 3762 previous cases for high grade Squamous Intraepithelial Lesions and Carcinoma-a College of American Pathologists Q-Probes study of 312 Institutions. Arch Pathol Lab Med 1995;119:1097-103.

7. Gustafsson L, Ponten J, Bergstrom R, Adami HO. International incidence rates of invasive cervical cancer before cytological screening. Int J Cancer 1997;71(2):159-65.

8. Gustafsson L, Ponten J, Zack M, Adami HO. International incidence rates of invasive cervical cancer after introduction of cytological screening. Cancer Causes Control 1997;8(5): 755-63.

9. Melamed MR, Hutchinson ML, Kaufman EA, Schecter CB, Garner D, Kobler TB, et al. Evaluation of costs and benefits of advances in cytologic technology: International Academy of Cytology Task Force Summary. Acta Cytol 1998;42(1):6975.

10. Brown AD, Garber AM. Cost-effectiveness of three methods to enhance the sensitivity of Papanicolaou testing. JAMA 1999;281(4):347-53.

11. McMeekin DS, McGonigle KF, Vasilev SA. Cervical cancer prevention: toward cost-effective screening. Medscape Womens Health 1997;2(12):1.

12. Frame PS, Frame JS. Determinants of cancer screening frequency: the example of screening for cervical cancer. J Am Board Fam Pract 1998;11(2):87-95.

13. McCrory DC, Mather DB, Bastian L, et al. Evaluation of cervical cytology. Evidence report/technology assessment No. 5. (Prepared by Duke University under Contract No. 290-97-0014. AHCPR Publication No. 99-E010.) Rockville, MD: Agency for Health Care Policy and Research; 1999.

14. Austin RM, Ramzy I. Increased detection of epithelial cell abnormalities by liquid-based gynecologic cytology preparations: a review of accumulated data. Acta Cytol 1998;42(1): 178-84.

15. Lee KR, Ashfaq R, Birdsong GG, Corkill ME, McIntosh KM, Inhorn SL. Comparison of conventional Papanicolaou smears and a fluid-based, thin-layer system for cervical cancer screening. Obstet Gynecol 1997;90(2):278-84.

16. Linder J. Automation in cytopathology. Am J Clin Pathol 1992;98(4 Suppl 1):S47-S51.

17. Linder J, Zahniser D. The ThinPrep Pap test: a review of clinical studies. Acta Cytol 1997;41(1):30-8.

18. Linder J. A decade has passed ... the Pap smear and cervical cancer [editorial; comment]. Am J Clin Pathol 1997;108(5): 492-8.

19. Linder J. Recent advances in thin-layer cytology. Diagn Cytopathol 1998;18(1):24-32.

20. McNeil C. The new Pap technologies: where they stand. J Natl Cancer Inst 1997;89(6):411.

21. McNeil C. New Pap test technologies embark on shifting seas. J Natl Cancer Inst 1997;89(6):410-12.

22. Papillo JL, Zarka MA, St. John TL. Evaluation of the ThinPrep Pap test in clinical practice: a seven-month, 16,314-case experience in northern Vermont. Acta Cytol 1998;42(1):203-8.

23. Sherman ME, Schiffman MH, Lorincz AT, Herrero R, Hutchinson ML, Bratti C, et al. Cervical specimens collected in liquid buffer are suitable for both cytologic screening and ancillary human papillomavirus testing. Cancer 1997;81(2): 89-97.

24. Sherman ME, Mendoza M, Lee KR, Ashfaq R, Birdsong GG, Corkill ME, et al. Performance of liquid-based, thin-layer cervical cytology: correlation with reference diagnoses and human papillomavirus testing [In Process Citation]. Mod Pathol 1998;11(9):837-43. 
25. Takahashi M, Kimura M, Akagi A, Naitoh M. AutoCyte SCREEN interactive automated primary cytology screening system: a preliminary evaluation. Acta Cytol 1998;42(1):185-8.

26. Wilbur DC, Cibas ES, Merritt S, James LP, Berger BM, Bonfiglio TA. ThinPrep Processor: clinical trials demonstrate an increased detection rate of abnormal cervical cytologic specimens [see comments]. Am J Clin Pathol 1994;101(2):209-14.

27. Wilbur DC, Dubeshter B, Angel C, Atkison KM. Use of thinlayer preparations for gynecologic smears with emphasis on the cytomorphology of high-grade intraepithelial lesions and carcinomas. Diagn Cytopathol 1996;14(3):201-11.

28. Williamson SL, Hair T, Wadehra V. The effects of different sampling techniques on smear quality and the diagnosis of cytological abnormalities in cervical screening. Cytopathology 1997;8(3):188-95.

29. Rosenthal DL. Automation and the endangered future of the Pap test. J Natl Cancer Inst 1998;90(10):738-49.

30. Patten SF Jr, Lee JS, Wilbur DC, Bonfiglio TA, Colgan TJ, Richart RM, et al. The AutoPap 300 QC System multicenter clinical trials for use in quality control rescreening of cervical smears: I. A prospective intended use study. Cancer 1998; 81(6):337-42.

31. Patten SF Jr, Lee JS, Wilbur DC, Bonfiglio TA, Colgan TJ, Richart RM, et al. The AutoPap 300 QC System multicenter clinical trials for use in quality control rescreening of cervical smears: II. Prospective and archival sensitivity studies. Cancer 1997;81(6):343-7.

32. Wilbur DC, Bonfiglio TA, Rutkowski MA, Atkison KM, Richart RM, Lee JS, et al. Sensitivity of the AutoPap 300 QC System for cervical cytologic abnormalities: biopsy data confirmation. Acta Cytol 1996;40(1):127-32.

33. Wilbur DC, Prey MU, Miller WM, Pawlick GF, Colgan TJ. The AutoPap system for primary screening in cervical cytology: comparing the results of a prospective, intended-use study with routine manual practice. Acta Cytol 1998;42(1):214-20.

34. Mango LJ, Radensky PW. Interactive neural-networkassisted screening: a clinical assessment. Acta Cytol 1998; 42(1):233-45.

35. Duggan MA, Brasher P. Paired comparison of manual and automated Pap test screening using the PAPNET system. Diagn Cytopathol 1997;17(4):248-54.

36. Radensky PW, Mango LJ. Interactive neural-networkassisted screening: an economic assessment. Acta Cytol 1998;42(1):246-52.

37. Michelow PM, Hlongwane NF, Leiman G. Simulation of primary cervical cancer screening by the PAPNET system in an unscreened, high-risk community. Acta Cytol 1997;41(1):8892.

38. Team PPM. Assessment of automated primary screening on PAPNET of cervical smears in the prismatic trial. Lancet 1999;353:1381-5.

39. Kreuger FAF, van Ballegooijen M, Doornewaard H. Is PAPNET suitable for primary screening? Lancet 1999;353:1374-5.

40. Stoler MH. The biology of papillomaviruses. Pathol Case Rev 1997;2(1):1-13.

41. Richart RM, Masood S, Syrjanen KJ, Vassilakos P, Kaufman RH, Meisels A, et al. Human papillomavirus: International Academy of Cytology Task Force summary. Diagnostic Cytology Towards the 21st Century: An International Expert Conference and Tutorial. Acta Cytol 1998;42(1):50-8.

42. Bosch FX, Manos MM, Munoz N, Sherman M, Jansen AM, Peto J, et al. Prevalence of human papillomavirus in cervical cancer: a worldwide perspective. International biological study on cervical cancer (IBSCC) Study Group [see comments]. J Nat Cancer Inst 1995;87(11):796-802.

43. Coutlee F, Mayrand MH, Provencher D, Franco E. The future of HPV testing in clinical laboratories and applied virology research. Clin Diagn Virol 1997;8(2):123-41.

44. Clavel C, Bory JP, Rihet S, Masure M, Duval-Binninger I,
Putaud I, et al. Comparative analysis of human papillomavirus detection by hybrid capture assay and routine cytologic screening to detect high-grade cervical lesions. Int J Cancer 1998;75(4):525-8.

45. Jenkins D, Sherlaw-Johnson C, Gallivan S. Can papilloma virus testing be used to improve cervical cancer screening? Int J Cancer 1996;65(6):768-73.

46. Schneider A. Virologic screening. Eur J Obstet Gynecol Reprod Biol 1996;65(1):61-3.

47. Cope JU, Hildesheim A, Schiffman MH, Manos MM, Lorincz AT, Burk RD, et al. Comparison of the hybrid capture tube test and PCR for detection of human papillomavirus DNA in cervical specimens. J Clin Microbiol 1997;35(9):2262-5.

48. Lorincz AT. Molecular methods for the detection of human papillomavirus infection. Obstet Gynecol Clin North Am 1996;23(3):707-30.

49. Lorincz AT. Hybrid Capture method for detection of human papillomavirus DNA in clinical specimens: a tool for clinical management of equivocal Pap smears and for population screening. J Obstet Gynaecol Res 1996;22(6):629-36.

50. Walboomers JM, Husman AM, Snijders PJ, Stel HV, Risse EK, Helmerhorst TJ, et al. Human papillomavirus in false negative archival cervical smears: implications for screening for cervical cancer. J Clin Pathol 1995;48(8):728-32.

51. van Ballegooijen M, van den Akker-van Marle ME, Warmerdam PG, Meijer CJ, Walboomers JM, Habbema JD. Present evidence on the value of HPV testing for cervical cancer screening: a model-based exploration of the (cost-)effectiveness. Br J Cancer 1997;76(5):651-7.

52. Jacobs MV, Snijders PJ, van den Brule AJ, Helmerhorst TJ, Meijer CJ, Walboomers JM. A general primer GP5+/GP6(+)mediated PCR-enzyme immunoassay method for rapid detection of 14 high-risk and 6 low-risk human papillomavirus genotypes in cervical scrapings. J Clin Microbiol 1997;35(3): 791-5.

53. Manos MM, Kinney WK, Hurley LB, Sherman ME, ShiehNgai J, Kurman RJ, et al. Identifying women with cervical neoplasia: using human papillomavirus DNA testing for equivocal Papanicolaou results [see comments]. JAMA 1999; 281(17):1605-10.

54. Frazer IH. The role of vaccines in the control of STDs: HPV vaccines. Genitourin Med 1996;72(6):398-403.

55. Gross G. Therapy of human papillomavirus infection and associated epithelial tumors. Intervirology 1997;40(5-6):368-77.

56. Hines JF, Ghim SJ, Jenson AB. Prospects for human papillomavirus vaccine development: emerging HPV vaccines. Curr Opin Obstet Gynecol 1998;10(1):15-9.

57. Lowy DR, Schiller JT. Papillomaviruses and cervical cancer: pathogenesis and vaccine development. J Natl Cancer Inst Monogr 1998;23:27-30.

58. McNeil C. HPV vaccines for cervical cancer move toward clinic, encounter social issues. J Natl Cancer Inst 1997;89(22):1664-6.

59. McNeil C. HPV vaccine treatment trials proliferate, diversify. J Natl Cancer Inst 1997;89(4):280-1.

60. Munoz N, Bosch FX. The causal link between HPV and cervical cancer and its implications for prevention of cervical cancer. Bull Pan Am Health Org 1996;30(4):362-77.

61. Sherman ME, Schiffman MH, Strickler H, Hildesheim A. Prospects for a prophylactic HPV vaccine: rationale and future implications for cervical cancer screening. Diagn Cytopathol 1998;18(1):5-9.

62. Steller MA, Schiller JT. Human papillomavirus immunology and vaccine prospects. J Natl Cancer Inst Monogr 1996;21:145-8.

63. Schneider A, Zahm DM. New adjunctive methods for cervical cancer screening. Obstet Gynecol Clin North Am 1996; 23(3):657-73.

64. Spitzer M. Cervical screening adjuncts: recent advances. Am J Obstet Gynecol 1998;179(2):544-56.

65. Baldauf JJ, Dreyfus M, Ritter J, Meyer P, Philippe E. Cervi- 
cography. Does it improve cervical cancer screening? Acta Cytol 1997;41(2):295-301.

66. van Niekerk WA, Dunton CJ, Richart RM, Hilgarth M, Kato H, Kaufman RH, et al. Colposcopy, cervicography, speculoscopy and endoscopy: International Academy of Cytology Task Force summary. Diagnostic Cytology Towards the 21st Century: An International Expert Conference and Tutorial. Acta Cytol 1998;42(1):33-49.

67. Loiudice L, Abbiati R, Boselli F, Cecchini G, Costa S, Grossi E, et al. Improvement of Pap smear sensitivity using a visual adjunctive procedure: a co-operative Italian study on speculoscopy (GISPE) [In Process Citation]. Eur J Cancer Prev 1998;7(4):295-304.

68. Richards-Kortum R, Mitchell MF, Ramanujam N, Mahadevan A, Thomsen S. In vivo fluorescence spectroscopy: potential for non-invasive, automated diagnosis of cervical intraepithelial neoplasia and use as a surrogate endpoint biomarker. J Cell Biochem Suppl 1994;19:111-9.

69. Ramanujam N, Mitchell MF, Mahadevan A, Thomsen S, Silva E, Richards-Kortum R. Fluorescence spectroscopy: a diagnostic tool for cervical intraepithelial neoplasia (CIN). Gynecol Oncol 1994;52(1):31-8.

70. Mahadevan-Jansen A, Mitchell MF, Ramanujam N, Malpica A, Thomsen S, Utzinger U, et al. Near-infrared Raman spectroscopy for in vitro detection of cervical precancers. Photochem Photobiol 1998;68(1):123-32.

71. Lee JH, Cho KS, Kim YM, Kim ST, Mun CW, Na JH, et al. Localized in vivo $1 \mathrm{H}$ nuclear MR spectroscopy for evaluation of human uterine cervical carcinoma. AJR Am J Roentgenol 1998;170(5):1279-82.

\section{Book Review}

\section{Brody JS: The Lung: Molecular Basis of Dis- ease, 218 pp, Philadelphia, W.B. Saunders Company, 1998 (\$52).}

In recent years, molecular biologic techniques have entered into the diagnostic clinical arena and are now powerful tools in the evaluation of neoplasms, infections, and genetic disorders, to name a few. Because of the rapid evolution and complexity of molecular biology, this area may seem intimidating to practicing physicians and students.

As the author states in the preface, the goal of this book is "to provide sufficient background to enable physicians and students to understand how molecular biology is now impacting on pulmonary practice and to be able to understand the coming advances." This concisely written, well-illustrated book largely achieves this goal and is an understandable introduction to molecular biology.

The book is organized into 10 chapters followed by a glossary of basic terminology. Chap- ter 1 reviews basic concepts of DNA and Southern, Northern, and Western blots. The subsequent chapters on tuberculosis, alveolar proteinosis, $\alpha_{1}$-antitrypsin, alveolar proteinosis, deficiency, cystic fibrosis, lung cancer, and AIDS are used to explain and illustrate basic molecular concepts and analysis such as polymerase chain reaction, DNA cloning, linkage analysis, oncogenes, and so forth.

Each chapter is clearly and concisely written and contains multiple tables and figures to make complex material very understandable. The bibliography for each chapter is relatively short but seems to contain a sufficient number of pertinent recent references. This text is well suited for students and practicing physicians (particularly pulmonologists) who desire a basic introduction to molecular biology.

\author{
Anita Dixon \\ Veterans Affairs Medical Center \\ Kansas City, Missouri
}

